\title{
Perhitungan Keandalan Pembangkit Loss of Load Probability (LOLP) untuk N unit Pembangkit
}

\author{
Reza Aditya Putra*1, Irna Tri Yuniahastuti ${ }^{2}$ \\ ${ }^{1,2}$ Universitas PGRI Madiun, Indonesia, Fakultas Teknik, Prodi Teknik Elektro \\ e-mail: *11rezaaditya808@gmail.com, ${ }^{2}$ irnatri@unipma.ac.id
}

\begin{abstract}
Abstrak
Perhitungan keandalan sistem tenaga listrik dapat dianalisis dari seberapa sering suatu sistem mengalami gangguan/seberapa sering listrik padam. Data hasil gangguan suatu sistem dapat dihitung menggunakan rumus LOLP (Loss of Load Probability). Semakin kecil nilai LOLP berarti suatu sistem semakin sedikit peluang mengalami gangguan dan investasi yang diperlukan untuk mendukung juga akan semakin besar. PLN mematok nilai risk level LOLP satu hari per tahun. Untuk perhitungan LOLP dapat dihitung dengan cara manual ataupun dengan program bantuan. Pada penelitian ini akan diusulkan program perhitungan menggunakan Matlab, dan dilakukan perbandingan hasil perhitungan dan waktu operasi sistem dengan menggunakan Mic Excell dan program Matlab. Hasil perhitungan LOLP dengan Excell dan Matlab mempuyai deviasi dibawah 1\%. Sehingga program yang diusulkan dinyatakan valid. Sedangkan waktu untuk memproses dengan Mic Excell dan Matlab didapatkan hasil yang sangat kontras. Hal ini disebabkan karena dengan penambahan unit pembangkit Mic Excell harus menghitung nilai LDC setiap penambahan pembangkit hal ini menyebabkan proses di excell membuat waktu lebih lama. Sedangkan waktu proses perhitungan dengan menggunakan Matlab didapatkan waktu yang lebih singkat dan input yang lebih sederhana.
\end{abstract}

Kata kunci - Keandalan pembangkit, LOLP, Matlab

\begin{abstract}
The calculation of the reliability of the electric power system can be analyzed from how often a system experiences interference / how often the power goes out. Data from the disturbance of a system can be calculated using the LOLP (Loss of Load Probability) formula. The smaller the LOLP value means that a system is less likely to experience disruption and the investment required to support it will also be even greater. PLN sets the LOLP risk level value one day per year. For LOLP calculations, it can be calculated manually or with an assistance program. In this study, a calculation program will be proposed using Matlab, and a comparison of the calculation results and system operating time using the Mic Excell and the Matlab program. The results of LOLP calculations with Excell and Matlab have a deviation of below 1\%. So that the proposed program is declared valid. Meanwhile, the processing time with Mic Excell and Matlab shows a very high contrast. This is because with the addition of the Mic Excell generating unit, you have to calculate the LDC value for each additional generator, this causes the Excell process to take longer. Meanwhile, the calculation process using Matlab obtained a shorter time and simpler input.
\end{abstract}

Keywords - LOLP, Matlab, Reliability of the electric power system 


\section{PENDAHULUAN}

Sistem keandalan pembangkit adalah kemampuan sistem untuk menyalurkan listrik ke semua titik penggunanya dalam standar dan jumlah yang sesuai yang dibutuhkan. Untuk mengkaji tentang keandalan perlu dilakukan perencanaan sistem tenaga listrik agar gangguan dapat diminimalisir. Kegagalan listrik yang sering terjadi adalah padamnya listrik yang dapat memberikan dampak tidak hanya di level rumah tangga namun juga pada level industri/ perusahaan. Jika padam terjadi pada industri yang bergerak pada produksi barang, hal ini dapat mempengaruhi hasil produksi sehingga kerugian tidak dapat terelakkan. Probabilitas pemadaman listrik dapat dikurangi dengan cara menaikkan investasi pada fase perencanaan dan pengoperasian.

Keandalan unit-unit pembangkit dipengaruhi oleh berbagai faktor antara lain gangguan kerusakan dan pemeliharaan rutin. Faktor-faktor tersebut memungkinkan unit-unit pembangkit mengalami gangguan yang dinyatakan dengan FOR (Forced Outage Rate) [1]. Forced outage rate adalah sebuah faktor yang menggambarkan sering tidaknya sebuah unit pembangkit mengalami ganguan, hal ini dialami oleh sebuah unit pembangkit dalam satu tahun (8760 jam) [2]. Suatu unit pembangkit dapat keluar dari sistem operasi sistem tenaga listrik karena suatu gangguan sehingga tidak dapat membangkitkan energi listrik. Gangguan ini disebabkan komponen tidak dapat melaksanakan fungsi sebenarnya akibat dari suatu atau beberapa kejadian. Gangguan dibedakan menjadi 2, yaitu [1]:

a. Gangguan paksa

adalah gangguan yang disebabkan oleh kondisi darurat yang berhubungan langsung dengan komponen/sistem/peralatan yang mengakibatkan komponen/peralatan harus dipisahkan dari sistem oleh suatu sistem proteksi secara otomatis atau manual oleh manusia

b. Gangguan terencana

adalah gangguan yang menyebabkan komponen/sistem dikeluarkan dari sistem. Hal ini biasanya dilakukan untuk perawatan komponen yang telah direncanakan.

Kemungkinan kehilangan beban atau LOLP (Loss of Load Probability) adalah perkalian Pxt. Jadi rumus secara umum adalah [3]

$$
L O L P=p x t
$$

LOLP dinyatakan dalam hari pertahun. Makin kecil nilai LOLP berarti daya yang terpasang harus makin tinggi serta force outage rate harus makin kecil dengan kata lain diperlukan investasi yang lebih besar untuk menjaga kualitas unit pembangkit yang lebih baik. Perhitungan $L O L P$ diperlukan dalam perencanaan operasi misalnya untuk menyusun jadwal pemeliharaan unit-unit pembangkit harus diatur sedemikian rupa sehingga daya tersedia tanpa force outage rate dari unit pembangkit mempunyai FOR tetap terpenuhi. PLN dalam menyusun jadwal pemeliharaan sistem interkoneksi Jawa mengambil risk level LOLP satu hari per tahun [3]. 
Nilai LOLP dipengaruhi oleh kurva beban harian, laju kegagalan paksa (force outage rate $=$ FOR) pembangkit, jumlah dan kapasistas unit pembangkit [4]. Perhitungan $L O L P$ dapat dilakukan baik secara perhitungan manual ataupun dengan menggunakan alat bantu (WASP IV, Matrix Laboratory/MATLAB). Perhitungan secara manual membutuhkan waktu yang lama apalagi jika jumlah pembangkit semakin banyak sehingga diperlukan program untuk mengatasi permasalahan tersebut agar diperoleh program yang cara kerjanya cepat dengan input yang sederhana. Beberapa penelitian menggunakan Microsoft Excel dan Matlab yaitu [5] [6] [7] [8] [9].

Pada penelitian [5] [8] perhitungan indeks keandalan LOLP dihitung secara manual/tanpa program, untuk kombinasi kapasitas daya yang digunakan menggunakan rumus binomial yang dihitung secara manual. Hal ini akan membutuhkan waktu yang lama ketika jumlah pembangkit yang dihitung banyak serta dibutuhkan ketelitian ekstra dalam perhitungan. Karena jika terjadi satu saja kesalahan maka, harus memulai perhitungan mulai awal.

Penelitian pada jurnal [6] [7] [9] menggunakan Matlab untuk perhitungan indeks keandalan pada pembangkit. Perhitungan menggunakan Matlab mempunyai kelebihan dari segi waktu dan data yang dibutuhkan antara lain FOR, kapasitas pembangkit, jumlah pembangkit dan data beban. Berdasarkan penelitian diatas, terdapat kekurangan dan kelebihan dari program perhitungan. Pada penelitan ini, akan digunakan perhitungan $\mathrm{N}$ pembangkit menggunakan Matlab dengan model yang lebih sederhana dan lebih cepat. Kelebihan penggunaan Matlab pada penelitian ini adalah input yang dimasukkan menggunakan variabel yang singkat serta pengguna hanya cukup memasukkan input secara manual dan semua proses akan dihitung dalam Matlab. Selain itu, program Matlab mampu menghitung nilai probabilitas kumulatif yang telah diurutkan secara sekaligus dalam waktu yang cepat. Validasi hasil perhitungan dengan menggunakan program ini akan dibandingkan dengan hasil penelitian [5] dan [3].

\section{METODE PENELITIAN}

\subsection{Flowchart Penelitian}

Flowchart pada penelitian ini disajikan pada Gambar 1. Nilai probabilitas kumulatif diperoleh berdasarkan nilai probabilitas individu. Nilai probabilitas individu pada pembangkit disajikan pada Tabel 1 dan Tabel 2.

Tabel 1. Data Gangguan Pada PT. Pupuk Sriwidjaja [5]

\begin{tabular}{cllccc}
\hline No & Tanggal Gangguan & Unit Generator & Daya (MW) & Lama Gangguan & FOR \\
\hline 1. & 25 Januari 2013 & Pusri- II & 15 & 105 menit & 0.1325 \\
2. & 4 Juni 2013 & Pusri-IV & 15 & 103 menit & 0.0667 \\
3. & 7 Juli 2013 & Pusri-III & 15 & 115 menit & 0.0667 \\
4. & - & Pusri-IB & 21.5 & - & 0.0667 \\
\hline
\end{tabular}

Nilai force outage rate Pusri-III dan Pusri-IB adalah dengan asumsi sama dengan force outage rate Pusri-IV [5]. 


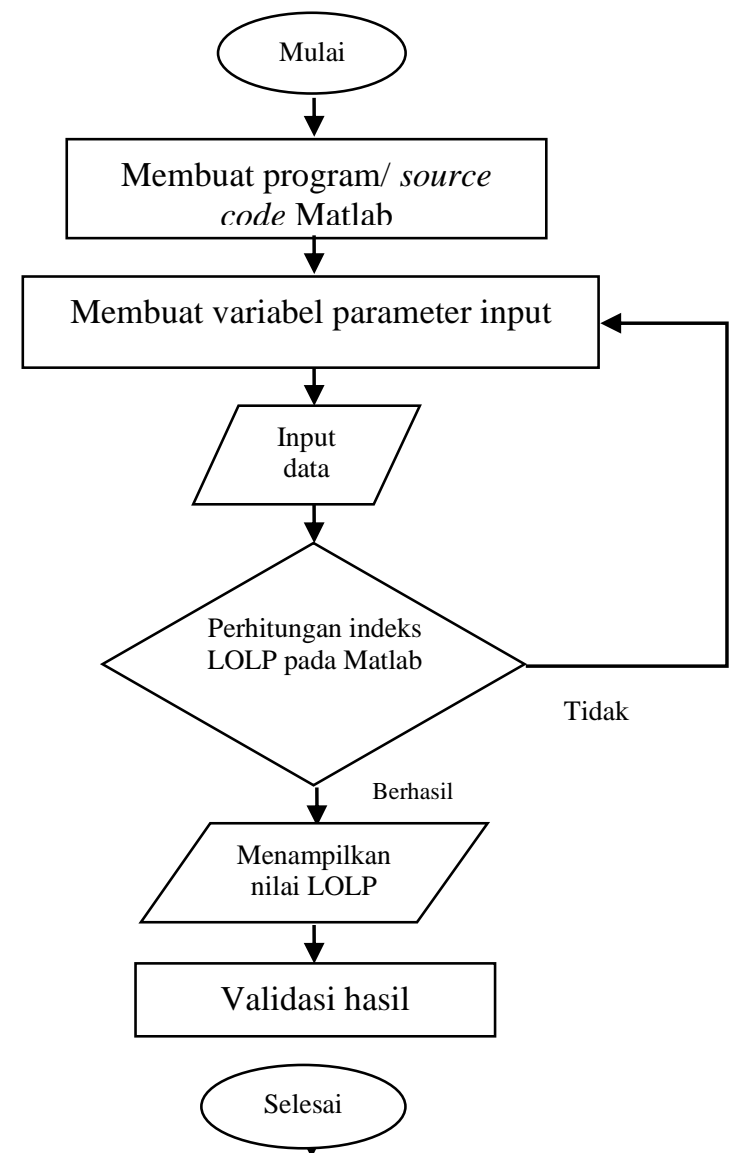

Gambar 1. Flowchart Penelitian

Alur pembuatan program perhitungan LOLP pada Matlab/source code disajikan pada Gambar 2.

$\begin{gathered}\text { Membuat kurva } \\ \text { lama beban }\end{gathered}$
$\begin{gathered}\text { Membuat Matrik } \\ \text { Kombinasi } \\ \text { Pembangkit }\end{gathered}$

Gambar 2. Pembuatan Source Code Pada Matlab

Tabel 2. Nilai Force Outage Rate Tiap Pembangkit [3]

\begin{tabular}{llcc}
\hline No & Unit Generator & Daya $(\mathrm{kW})$ & FOR \\
\hline 1. & Unit I & 500 & 0.01 \\
\hline 2. & Unit II & 1000 & 0.06 \\
\hline 3. & Unit III & 1000 & 0.06 \\
\hline 4. & Unit IV & 1250 & 0.05
\end{tabular}

\subsection{Implementasi Program Matlab pada perhitungan LOLP}

Fungsi yang digunakan pada program Matlab antara lain sortrows, polyfit, polyval, binopdf dan binocdf. Sortrows berfungsi mengurutkan data dari yang terkecil 
ke terbesar ataupun sebaliknya. Data yang dimaksud adalah data kurva lama beban dan kombinasi kapasitas pembangkit. Persamaan (2) menunjukkan fungsi sortrows untuk membentuk LDC (Load Duration Curve) dan persamaan (3) fungsi sortrows untuk membentuk kombinasi pembangkit yang telah diurutkan [10]

$$
\begin{aligned}
& L D C=\operatorname{sortrows}(\text { kurva_beban, },-1) \\
& \text { Mixed }=\text { sortrows }(\text { mixed },-1)
\end{aligned}
$$

Fungsi polyfit digunakan untuk mencari koefisien persamaan polinomial dari data $L D C$ yang telah diurutkan dari data terbesar. Fungsi polyval berfungsi untuk membuat kurva dan persamaan dari koefisien yang telah diketahui. Kurva $L D C$ digunakan untuk menentukan kemampuan sebuah kombinasi pembangkit untuk menyuplai beban yang ada. Jika terjadi kapasitas daya lebih kecil dari beban maka sistem akan kehilangan beban. Persamaan (4) menunjukkan persamaan fungsi polyfit.

$$
\text { Coef }=\text { poly fit }(\text { LDCload }, n, 4))
$$

Fungsi binopdf digunakan untuk mencari nilai kemungkinan individu dari setiap kombinasi pembangkit. Sedangkan binocdf digunakan untuk menghitung kemungkinan kumulatif dari setiap kombinasi pembangkit. Nilai kemungkinan individu dan kemungkinan kumulatif disajikan pada Tabel 3 dan Tabel 4.

Tabel 3. Nilai P Kumulatif Dari Jurnal [5]

\begin{tabular}{ccc}
\hline No & $\begin{array}{c}\text { Kapasitas Tersedia } \\
(\mathrm{MW})\end{array}$ & P Individual \\
\hline 1. & 66.5 & 0.705234063 \\
2. & 51.5 & 0.208517563 \\
3. & 45 & 0.050400849 \\
4. & 36.5 & 0.018998214 \\
5. & 30 & 0.014902991 \\
6. & 21.5 & 0.00055016 \\
\hline
\end{tabular}

Tabel 4. Nilai P Kumulatif Dari [3]

\begin{tabular}{cccc}
\hline No & Kapasitas tersedia $(\mathrm{kW})$ & P Individual & P Kumulatif \\
\hline 1. & 3750 & 0.8310258 & 1 \\
2. & 3500 & 0.0083942 & 0.1689742 \\
3. & 3250 & 0.0083942 & 0.16058 \\
4. & 2750 & 0.0530442 & 0.0544916 \\
5. & 2500 & 0.0437382 & 0.0107534 \\
6. & 2250 & 0.0005358 & 0.0096818 \\
7. & 2000 & 0.0004418 & 0.00924 \\
8. & 1750 & 0.0033858 & 0.0058542 \\
9. & 1500 & 0.0027918 & 0.0002706 \\
10. & 1250 & 0.0000342 & 0.0002364 \\
11. & 1000 & 0.0000282 & 0.00018 \\
12. & 0 & 0.0000018 & 0.0000018 \\
\hline
\end{tabular}




\section{HASIL DAN PEMBAHASAN}

Berdasarkan hasil perhitungan dengan menggunakan model yang dibuat pada penelitian ini dan perbandingan dengan hasil penelitian pada [5] dan [3], diperoleh hasil yang ditunjukkan pada Tabel 5

\section{Tabel 5. Perbandingan Nilai Hasil Penelitian Dengan Program Yang Diusulkan}

\begin{tabular}{cccc}
\hline Jurnal Rujukan & Hasil Penelitian & $\begin{array}{c}\text { Hasil Program Yang } \\
\text { Diusulkan }\end{array}$ & Deviasi \\
\hline$[5]$ & 2.48502436 & 2.485567689 & $0.01 \%$ \\
{$[3]$} & 1.69477 & 1.695111235 & $0.01 \%$ \\
\hline
\end{tabular}

Berdasarkan Tabel 5, nilai deviasi kurang dari $1 \%$ yang menyatakan bahwa model perhitungan ini valid. Perbedaan perhitungan tersebut disebabkan pembulatan pada perhitungan excel yang berbeda dengan Matlab. Data yang dibutuhkan sebagai input di Matlab yaitu jumlah unit, kapasitas pembangkit dan nilai FOR. Jumlah pembangkit dapat diubah-ubah hal tersebut sesuai dengan tujuan penelitian ini yaitu model perhitungan $\mathrm{N}$ unit pembangkit. Semakin banyak jumlah pembangkit maka akan semakin banyak jumlah kombinasi pembangkit sehingga menyebabkan iterasi pada Matlab juga akan membutuhkan penambahan waktu. Berlaku pula jika jumlah pembangkit dikurangi. Perbandingan waktu perhitungan menggunakan excell dan Matlab disajikan pada Tabel 6. Jumlah pembangkit yang dihitung sebanyak 4 unit

Tabel 6. Perbandingan Waktu Proses Perhitungan

\begin{tabular}{ccc}
\hline \multirow{2}{*}{ Jurnal rujukan } & \multicolumn{2}{c}{ Waktu perhitungan } \\
\cline { 2 - 3 } & Mic. Excell & Matlab \\
\hline$[5]$ & 1200 detik & 2 detik \\
{$[3]$} & 1300 detik & 2.4 detik \\
\hline
\end{tabular}

Berdasarkan Tabel 6 didapatkan hasil waktu perhitungan yang sanat berbeda antara Excell dan Matlab. Hal ini disebabkan, semua perhitungan dalam Matlab dilakukan secara otomatis tersimpan dalam memori sehingga tidak lagi menggunakan perhitungan manual. Pada perhitungan manual, hal yang mempengaruhi antara lain kecepatan pengguna dalam mengoperasikan Matlab dan jumlah unit. Sedangkan pada Matlab dipengaruhi oleh spesifikasi komputer dan jumlah unit.

Pada Gambar 3, menunjukkan komposisi waktu perhitungan pada setiap unit N unit pembangkit.

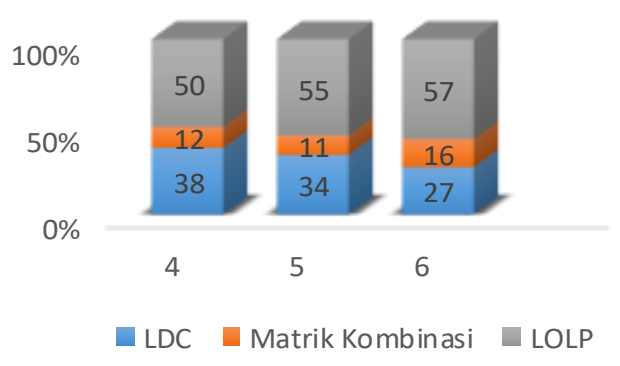

Gambar 3. Waktu Perhitungan N Unit Pembangkit 


\section{KESIMPULAN}

Perhitungan keandalan $\mathrm{N}$ unit pembangkit dapat digunakan untuk perhitungan $L O L P$ dengan waktu yang lebih cepat dan input yang lebih sedehana. Deviasi perhitungan $L O L P$ antara jurnal dan perhitungan program yang diusulkan sebesar kurang dari $1 \%$. Sehingga pemodelan dengan menggunakan $N$ unit pembangkit ini dapat digunakan secara valid.

\section{DAFTAR PUSTAKA}

[1] Syahrial, K. Sawitri and P. Gemahapsari, "Studi Keandalan Ketersediaan Daya Pembangkit Listrik pada Jaringan Daerah "X"," Jurnal ELKOMNIKA, vol. 5, no. 1, pp. 93-105, 2017.

[2] D. Marsudi, Pembangkitan Energi Listrik, Jakarta: Erlangga, 2005.

[3] D. Marsudi, Operasi Sistem Tenaga Listrik, Yogyakarta: Graha Ilmu, 2006.

[4] R. F. S. Budi, M. D. Birmano and I. Bastoni, "Pemodelan Perhitungan Indeks Lost of Load Probability untuk N Unit Pembangkit pada Sistem Kelistrikan Opsi Nuklir," Jurnal Pengembangan Energi Nuklir, vol. 19, no. No. 2, pp. 61-68, 2017.

[5] R. Apriani and R. Thayib, "Perhitungan Loss of Load Probability (Probabilitas Kehilangan Beban) Sistem Tenaga Listrik di PT Pupuk Sriwidjaja," Mikrotiga, vol. 2, no. No. 1, pp. 22-27, 2015.

[6] A. N. Widiastuti, Sarjiya, K. A. Pinanditho and E. T. Prastyo, "Evaluasi Keandalan Perencanaan Pembangkit WIlayah Jawa-Bali dengan Mempertimbangkan Ketidakpastian Peramalan Beban," JNETI, vol. 6, no. 2, pp. 230-234, 2017.

[7] M. Subekti, U. B. Sudibyo and I. M. Ardit, "Analisis Keandalan Perencanaan Pembangkit Listrik PLN Region 3 tahun 2008-2017," in Prosiding Seminar Nasional Teknoin 2008 Bidang Teknik ELektro, Yogyakarta, 2008.

[8] A. Syukri, I. N. Sumerta and M. I. BS, "Evaluasi Keandalan Pembangkit Listrik Tenaga Uap di PT PJB Unit Pembangkitan Paiton," Jurnal Penelitian Teknik Elektro, vol. 3, no. 4, pp. 109-114, Desember 2010.

[9] G. A. P. Yoga, H. Gusmedi, O. Zebua and L. Hakim, "Analisa Keandalan Sistem Tenaga Listrik di Wilayah Lampung berdasarkan Ketersediaan Daya pada Tahun 2016," in Konferensi Ilmiah Nasional Mahasiswa Indonesia 2017, Lampung, 2017.

[10] M. Shahbanzadeh and M. Heldarizadeh, "Power System Reability Indices Calculation (such as LOLP and EENS) using Matlab," Reasrchgate, January 2008. 